\title{
Effects of salinity build-up on the performance and bacterial community structure of a membrane bioreactor
}

\author{
Submitted to Bioresource Technology
}

September 2015

Wenhai Luo ${ }^{\mathrm{a}}$, Hop V. Pha ${ }^{\mathrm{a}}$, Faisal I. Hai ${ }^{\mathrm{a}}$, William E. Price ${ }^{\mathrm{b}}$, Wenshan Guo ${ }^{\mathrm{c}}$, Hao H. Ngo ${ }^{\mathrm{c}}$, Kazuo Yamamoto ${ }^{\mathrm{d}}$, Long D. Nghiem ${ }^{\mathrm{a}^{*}}$

${ }^{a}$ Strategic Water Infrastructure Laboratory, School of Civil, Mining and Environmental Engineering, University of Wollongong, Wollongong, NSW 2522, Australia

${ }^{b}$ Strategic Water Infrastructure Laboratory, School of Chemistry, University of Wollongong, Wollongong, NSW 2522, Australia

${ }^{c}$ Centre for Technology in Water and Wastewater, School of Civil and Environmental Engineering, University of Technology Sydney, Sydney, NSW 2007, Australia

${ }^{d}$ Environmental Science Centre, University of Tokyo, Tokyo 113-0033, Japan

\footnotetext{
* Corresponding author: longn@uow.edu.au; Ph: +61 (2) 42214590.
} 


\begin{abstract}
This study investigated the effects of salinity increase on bacterial community structure in a membrane bioreactor (MBR) for wastewater treatment. The influent salt loading was increased gradually to simulate salinity build-up in the bioreactor during the operation of a high retention - membrane bioreactor (HR-MBR). Bacterial community diversity and structure were analysed using 454 pyrosequencing of 16S rRNA genes of MBR mixed liquor samples. Results show that salinity increase reduced biological performance but did not affect microbial diversity in the bioreactor. Unweighted UniFrac and taxonomic analyses were conducted to relate the reduced biological performance to the change of bacterial community structure. In response to the elevated salinity condition, the succession of halophobic bacteria by halotolerant/halophilic microbes occurred and thereby the biological performance of MBR was recovered. These results suggest that salinity build-up during HR-MBR operation could be managed by allowing for the proliferation of halotolerant/halophilic bacteria.
\end{abstract}

Key words: Membrane bioreactor (MBR); Salinity build-up; 454 pyrosequencing; bacterial community; microbial diversity. 


\section{Introduction}

Water scarcity, exacerbated by climate change, population growth, and industrialization, has accelerated the use of alternative water sources, including reclaimed water (Shannon et al., 2008). Wastewater reclamation also effectively addresses environmental pollution. Thus, many dedicated attempts have been made to develop robust and highly efficient technologies, such as membrane bioreactor (MBR), for wastewater treatment and reuse (Melin et al., 2006). MBR integrates activated sludge treatment with membrane separation processes, such as microfiltration (MF) or ultrafiltration (UF). Compared with conventional activated sludge treatment, MBR has several advantages, including higher effluent quality, lower sludge production, and smaller physical footprint (Hai et al., 2014).

Further development of MBR has recently led to the formation of the high retention membrane bioreactor (HR-MBR) concept (Lay et al., 2010; Luo et al., 2014). Currently, there are three HR-MBR variations, namely osmotic membrane bioreactor (OMBR) (Achilli et al., 2009; Nawaz et al., 2013; Nguyen et al., 2015), membrane distillation bioreactor (Phattaranawik et al., 2008; Wijekoon et al., 2014), and nanofiltration membrane bioreactor (NF-MBR) (Choi et al., 2002; 2006). In these systems, the forward osmosis, membrane distillation, and nanofiltration membranes are utilized to extract treated water from the bioreactor mixed liquor. By employing these high retention membrane processes, the HRMBR systems can potentially produce high quality reusable water, particularly for regions facing severe freshwater scarcity and with stringent environmental regulations.

A major challenge to the development of HR-MBR is to manage salinity build-up in the bioreactor. High retention membranes can effectively reject inorganic salts, resulting in their accumulation or build-up in the bioreactor during HR-MBR operation (Lay et al., 2010). A high saline state can also occur in the case of a conventional MBR due to seawater intrusion or during the treatment of highly saline wastewaters from seafood processing or the dairy industry (Reid et al., 2006).

It is well established that an elevated salinity condition can adversely affect MBR performance. Reid et al. (2006) observed that an increase in bioreactor salinity to $5 \mathrm{~g} / \mathrm{L}$ sodium chloride $(\mathrm{NaCl})$ increased the concentrations of soluble microbial products and extracellular polymeric substances in the mixed liquor and thus severely reduced the membrane permeability. Yogalakshmi and Joseph (2010) reported a reduction in biological performance as the bioreactor salinity increased. Jang et al. (2013) and Hong et al. (2013) 
subsequently attributed the reduced biological performance to the change of bacterial community structure in the highly saline environment of the bioreactor. Evidence of bacterial changes in response to the elevated salinity has also been reported by Qiu and Ting (2013) who investigated microbial community dynamics during OMBR operation. In these studies, denaturing gradient gel electrophoresis (DGGE) was applied to elucidate microbial response to the increase in bioreactor salinity. It is noteworthy that DGGE is a fingerprinting method and can only provide information of abundant microbial species (Boon et al., 2002).

Moreover, crowding of DGGE bands due to identical positions of some bacteria in the gel may underestimate microbial diversity (Nübel et al., 1999; Choi et al., 2007).

In this study, high-throughput 454 pyrosequencing was used to systematically investigate impacts of salinity increase on the bacterial community structure of a conventional MBR equipped with an MF membrane. Basic performance of the MBR with salinity increase was also evaluated in terms of contaminant removal. The increase in bioreactor salinity simulated here was relevant to the range often encountered in HR-MBR operation. Thus, the results allow for a better understanding and potentially the ability to manage salinity build-up in the bioreactor during HR-MBR operation.

\section{Materials and methods}

\subsection{Experimental system and operational protocol}

Two identical lab-scale MBR systems were used in this study. Detailed description of the MBR systems is available elsewhere (Luo et al., 2015). Briefly, each MBR system comprised a feed reservoir, an aerobic bioreactor and a submerged hollow fibre MF membrane module made of polyvinylidene fluoride (Mitsubishi Rayon Engineering, Tokyo, Japan). The MF membrane module had an effective surface area and a nominal pore size of $740 \mathrm{~cm}^{2}$ and $0.4 \mu \mathrm{m}$, respectively. A Masterflex peristaltic pump (Cole-Parmer, Vernon Hills, IL) controlled by a computer was used to extract treated water through the MF membrane in a cycle of 14 min suction and 1 min off.

Activated sludge collected from the Wollongong Wastewater Treatment Plant (Wollongong, New South Wales, Australia) was acclimatized in the two MBR systems under the same conditions. A synthetic wastewater (Supplementary Information, Table S1), simulating medium strength municipal sewage, was used as the MBR influent. The mixed liquor suspended solids (MLSS) concentration in the two bioreactors was maintained at approximately $5 \mathrm{~g} / \mathrm{L}$ by regular sludge wastage, which corresponded to the sludge retention 
time (SRT) of 50 days. The hydraulic retention time (HRT) was maintained at 24 hours. The bioreactors were continuously aerated to obtain dissolved oxygen (DO) concentration of approximately $5 \mathrm{mg} / \mathrm{L}$. The bioreactor temperature was maintained at $26 \pm 1^{\circ} \mathrm{C}$ using a temperature-controlled water bath.

Once acclimatized in terms of bulk organic removal (i.e. over $97 \%$ total organic carbon (TOC) removal), the influent salinity of an MBR system (denoted "saline-MBR") was increased by enhancing the $\mathrm{NaCl}$ loading from 0 to $16.5 \mathrm{~g} / \mathrm{L}$ with a gradient of $0.5 \mathrm{~g} / \mathrm{L} \cdot$ day (Supplementary Information, Fig. S1). The range of salinity build-up simulated here was similar to that would occur during normal OMBR operation (Supplementary Information, Appendix A). To allow microbial adaptation to the highly saline condition, the influent $\mathrm{NaCl}$ loading was maintained at 10 and $16.5 \mathrm{~g} / \mathrm{L}$ for 14 and 25 days, respectively. Therefore, the saline-MBR was continuously operated for 70 days (excluding the acclimatization period). Another MBR system (denoted "control-MBR”) was operated concurrently under identical conditions, but without any increase in the influent salinity.

Mixed liquor samples were collected from the two MBR systems for microbial analysis on days $0,33,43$, and 70 of the experiment, corresponding to $0,10,15$ and $16.5 \mathrm{~g} / \mathrm{L} \mathrm{NaCl}$ loading in the saline-MBR.

\subsection{Microbial community analysis}

\subsubsection{DNA extraction and 454 sequencing}

Genomic DNA was extracted from all mixed liquor samples using the FastDNA ${ }^{\circledR}$ SPIN Kit for soil (MP Biomedicals, Santa Ana, CA). The integrity, purity and concentration of the extracted DNA were evaluated by electrophoresis in a $1 \%(\mathrm{w} / \mathrm{v})$ agarose gel and the NanoDrop ${ }^{\circledR}$ ND-1000 spectrophotometer (NanoDrop Technologies, Wilmington, DE).

DNA samples were stored at $-20{ }^{\circ} \mathrm{C}$ and then shipped to the Australian Genome Research Facility (Brisbane, Queensland, Australia) for amplicon pyrosequencing using a standard Roche 454/GS-FLX platform. Bacterial domain was targeted by selecting V1 - V3 regions of the 16S rRNA genes with primers 27F (5'- AGAGTTTGATCMTGGCTCAG-3') and 519R (5'- GWATTACCGCGGCKGCTG-3').

\subsubsection{Sequence analysis}

Raw pyrosequencing data were analysed using the Quantitative Insights into Microbial Ecology software (QIIME 1.9.1) (Caporaso et al., 2010a). By using the "split_libararies.py" script, we removed defective sequences that contained ambiguous bases, had errors in the 
barcode or primer, a length outside the range 200 to $1000 \mathrm{nt}$, homopolymers greater than $6 \mathrm{nt}$, or an average quality score less than 25 . The remaining sequences were denoised using the “denoise_wrapper.py" script and then clustered into operational taxonomic units (OTUs) using the GreenGenes 16S rDNA database with uclust based on the similarity of 97\% (Edgar, 2010). OTUs containing less than two sequences (i.e. singletons) were excluded from the downstream analysis. The representative sequence of each OTU was aligned to the GreenGenes 16S rDNA database using PyNast (Caporaso et al., 2010b). Chimeric sequences were identified by ChimeraSlayer (Haas et al., 2011) and subsequently removed from the OTUs using a python script. A Netwick formatted phylogenetic tree was constructed by employing FastTree (Price et al., 2010).

Both $\alpha$ - and $\beta$-diversity metrics were determined using a default setting in QIIME based on the even sequencing depth of 13000 (i.e. the lowest sequences of each sample) to avoid the heterogeneity related to different sequencing depths. Specifically, $\alpha$-diversity metrics included Chao1, Shannon index, and phylogenetic diversity, and $\beta$-diversity were indicated by the UniFrac distance metrics. Principal coordinate analysis (PCoA) and unweighted pair group method with arithmetic mean were used to present the UniFrac distance metrics for comparing bacterial community structures in all mixed liquor samples. Good's coverage was calculated to evaluate the completeness of sampling and the possibility that an amplicon sequence selected randomly has already been sequenced. All sequencing data in this study are available at the Sequence Read Archive with accession number SRP063682 in the National Centre for Biotechnology Information.

\subsection{Water quality measurement}

TOC was measured by a TOC analyser (TOC-V $\mathrm{V}_{\mathrm{CSH}}$, Shimadzu, Kyoto, Japan). Ammonium $\left(\mathrm{NH}_{4}{ }^{+}-\mathrm{N}\right)$ was analysed using a Flow Injection Analysis system (QuikChem8500, Lachat, CO). Solution $\mathrm{pH}$ and conductivity were measured using an Orion 4-Star Plus $\mathrm{pH} /$ conductivity meter (Thermo Scientific, Waltham, MA).

\section{Results and discussion}

\subsection{Removal of organic matter and ammonia}

Salinity increase within the bioreactor impacted the biological performance of MBR. As shown in Fig. 1, the removal of TOC and $\mathrm{NH}_{4}{ }^{+}-\mathrm{N}$ by the control-MBR was above $98 \%$ throughout the experiment. By contrast, an initial reduction and subsequent increase in their removals by the saline-MBR was observed as the influent salt $(\mathrm{NaCl})$ loading increased. This 
observation is consistent with previous studies (Hong et al., 2013; Jang et al., 2013). The highly saline condition could result in cell plasmolysis, inhibit microbial activity, and eventually deteriorate the MBR biological performance (Hong et al., 2013). Nevertheless, microbial acclimatization to the saline environment of the bioreactor could recover the biological performance of MBR (Jang et al., 2013).

\section{[FIGURE 1]}

\subsection{Microbial community dynamics}

\subsubsection{Microbial diversity and structure}

Similar $\alpha$-diversity metrics (i.e. Chao 1 value, Observed OTUs, Shannon index, and phylogenetic diversity) were observed between the control- and saline-MBRs (Fig. 2). As noted in section 2.1, mixed liquor samples were collected when the influent $\mathrm{NaCl}$ loading of the saline-MBR was above $10 \mathrm{~g} / \mathrm{L}$. Thus, it is possible that halotolerant and/or halophilic bacteria replaced salt-sensitive or halophobic microbes with salinity increase in the salineMBR, resulting in similar microbial diversity in the two systems (Zhang et al., 2013). Nevertheless, small fluctuations of these diversity metrics over time were observed for both MBRs (Fig. 2), possibly due to natural and temporal variation of bacteria. Similar variations have been reported by Choi et al., (2007) who compared the microbial diversity between NFMBR and MF-MBR using the DGGE technology. Good's coverage values were higher than 98\% for all mixed liquor samples in this study, indicating that the sequence library represented most species in those samples.

\section{[FIGURE 2]}

Despite the similar diversity between the control- and saline-MBRs, hierarchical clustering based on the unweighted UniFrac metric shows significant differences in bacterial community structure in these two systems (Fig. 3). Mixed liquor samples collected from the saline-MBR after salt $(\mathrm{NaCl})$ loading formed clusters distinct from those without salinity increase (i.e. samples obtained from the control-MBR and the saline-MBR before the addition of $\mathrm{NaCl}$ ). This observation indicates that the elevated salinity led to the development of different bacterial communities in the bioreactor. Furthermore, different clusters were also observed for samples obtained over time from both MBRs, probably due to natural variation of bacteria.

\section{[FIGURE 3]}


Clustering obtained from the UniFrac analysis was further examined by PCoA (Fig. 4).

Along the PC1 vector, similar bacterial communities were observed for non-saline samples (collected from the control-MBR and the saline-MBR before $\mathrm{NaCl}$ addition). By contrast, salinity increase modified bacterial communities in the bioreactor. Despite the close PCoA plots for all saline samples (obtained from the saline-MBR at influent $\mathrm{NaCl}$ loading of 10 $16.5 \mathrm{~g} / \mathrm{L})$, they were clearly distinguishable from those of non-saline samples in the PC1 vector (Fig. 4). Additionally, natural variation of microbial communities also occurred during MBR operation, as indicated by different PCoA plots of mixed liquor samples taken over time from both control- and saline-MBRs along the PC2 vector.

\section{[FIGURE 4]}

\subsubsection{Bacterial community structure}

Taxonomic analysis revealed the variation of bacterial community structure in response to salinity increase in the bioreactor (Figs. 5 and 6). Compared to the control-MBR, salinity increase in the saline-MBR reduced the abundance of several bacterial phyla, including Planctomycetes, Verrucomicrobia, Bacteroidetes, Armatimonadetes and Gemmatimonadetes

(Fig. 5). A reduction in the abundance of these bacterial phyla along a salinity gradient was also observed in a Chinese wetland (Zhang et al., 2013) and the Baltic Sea (Herlemann et al., 2011). Further analysis at the order level showed the growth of some bacterial orders, such as Phycisphaerales in Planctomycetes and SJA-22 in Armatimonadetes, in the control-MBR. By contrast, they were absent in the saline-MBR with an increase in salinity (Fig. 6). The osmotic pressure of highly saline environment of the bioreactor could result in the dehydration and plasmolysis of microbial cells, and eventually causing the extinction of halophobic bacteria (Lay et al., 2010). As a result, the biological treatment of MBR was adversely affected by the elevated salinity at the beginning of the experiment (Fig. 1).

\section{[FIGURE 5]}

\section{[FIGURE 6]}

Elevated salinity, on the other hand, facilitated the dominance of some bacterial groups (Figs. 5 and 6). Proteobacteria was the most abundant phylum in both control- and salineMBRs, and its abundance enhanced with salinity increase (Fig. 5). The enhanced abundance of the phylum Proteobacteria in the saline-MBR was mainly contributed by the class $\alpha$ - and $\gamma$-proteobacteria (Supplementary Information, Fig. S2). The predominance of $\alpha$ proteobacteria could be further attributed to the order Rhizobiales, followed by 
Sphingomonadales and Rhodobacterales. The orders Xanthomonadales, Pseudomonadales, and Enterobacteriales were main contributors to the elevated abundance of $\gamma$-proteobacteria in the saline-MBR with salinity increase (Fig. 6). Similar results have been reported by Zhang et al. (2013) who observed an increase in the relative abundance of the class $\alpha$ - and $\gamma$ proteobacteria along a salinity gradient in a wetland. Despite the significantly lower abundance of the phylum Bacteroidetes in the saline-MBR compared to the control reactor, its members Flavobacteriales and Saprospirales were more abundant in the saline-MBR. Indeed, members of the phylum Bacteroidetes are usually dominant in both marine and freshwater environment (Zhang et al., 2013). In addition, the order Burkholderiales in $\beta$ proteobacteria was also more abundant in the saline-MBR than that in the control system.

Detailed analysis at the genus level identified the dominant genera of salt-tolerant and/or halophilic bacteria in the saline-MBR (Supplementary Information, Fig. S3). The genera Hyphomicrobium and Rhodoplanes affiliated to the order Rhizobiales became more abundant in the saline-MBR with salinity increase. Furthermore, some genera were only present in the saline-MBR after the addition of $\mathrm{NaCl}$, such as Shingopyxis in Sphingomonadales,

Hyphomonas in Rhodobacterales, and Shewanella in Alternomonadales. Membranes of these genera commonly exist in marine environment and require certain salinity for proliferation (Casamayor et al., 2000). As a result, the recovery of the biological performance of the saline-MBR (section 3.1) could be attributed to the growth of these salt-tolerant and/or halophilic bacteria, which supplemented the decrease in halophobic microbes with salinity increase in the bioreactor.

Despite the high removal of $\mathrm{NH}_{4}{ }^{+}-\mathrm{N}$ by both control- and saline-MBRs (Fig. 1), two relevant bacterial groups (i.e. ammonia-oxidizing archaea and bacteria) were not effectively detected in these systems. This result was possibly due to the presence of ammonia-oxidizing archaea and bacteria that were unidentifiable by pyrosequencing of $16 \mathrm{~S}$ rRNA genes. Similar results were also reported by Zhang et al. (2012) who investigated bacterial diversity of activated sludge from different sewage treatment plants using 454 pyrosequencing.

\section{Conclusion}

Results reported here show that the bacterial community in MBR is highly diverse and resilient. Bacterial community diversity and structure analyses using 454 pyrosequencing of 16S rRNA genes of the MBR mixed liquor revealed the succession of halophobic microbes by halotolerant and/or halophilic bacteria with salinity increase. Thus, the elevated salinity 
did not affect the microbial diversity of the bioreactor. The results suggest that salinity buildup in the bioreactor during HR-MBR operation could be potentially managed by allowing for the proliferation of halotolerant and/or halophilic bacteria.

\section{Acknowledgement}

This research was supported under Australian Research Council's Discovery Project funding scheme (project DP140103864). Wenhai Luo would like to thank the Chinese Scholarship Council and the University of Wollongong for PhD scholarship support.

\section{References}

[1] Achilli, A., Cath, T.Y., Marchand, E.A., Childress, A.E., 2009. The forward osmosis membrane bioreactor: A low fouling alternative to MBR processes. Desalination 239, $10-21$.

[2] Boon, N., De Windt, W., Verstraete, W., Top, E.M., 2002. Evaluation of nested PCRDGGE (denaturing gradient gel electrophoresis) with group-specific 16S rRNA primers for the analysis of bacterial communities from different wastewater treatment plants. FEMS Microbiol. Ecol. 39, 101-112.

[3] Caporaso, J.G., Kuczynski, J., Stombaugh, J., Bittinger, K., Bushman, F.D., Costello, E.K., Fierer, N., Peña, A.G., Goodrich, J.K., Gordon, J.I., Huttley, G.A., Kelley, S.T., Knights, D., Koenig, J.E., Ley, R.E., Lozupone, C.A., McDonald, D., Muegge, B.D., Pirrung, M., Reeder, J., Sevinsky, J.R., Turnbaugh, P.J., Walters, W.A., Widmann, J., Yatsunenko, T., Zaneveld, J., Knight, R., 2010a. QIIME allows analysis of highthroughput community sequencing data. Nat. Methods 7, 335-336.

[4] Caporaso, J.G., Bittinger, K., Bushman, F.D., DeSantis, T.Z., Andersen, G.L., Knight, R.,2010b. PyNAST: a flexible tool for aligning sequences to a template alignment. Bioinformatics 26, 266-267.

[5] Casamayor, E.O., Calderón-Paz, J.I., Pedrós-Alió, C., 2000. 5S rRNA fingerprints of marine bacteria, halophilic archaea and natural prokaryotic assemblages along a salinity gradient. FEMS Microbiol. Ecol. 34, 113-119.

[6] Choi, J.H., Dockko, S., Fukushi, K., Yamamoto, K., 2002. A novel application of a submerged nanofiltration membrane bioreactor (NF MBR) for wastewater treatment. Desalination 146, 413-420. 
[7] Choi, J.H., Fukushi, K., Yamamoto, K., Ng, H.Y., 2006. Evaluation of a long-term operation of a submerged nanofiltration membrane bioreactor (NF MBR) for advanced wastewater treatment. Water Sci. Technol. 53, 131-136.

[8] Choi, J.H., Lee, S.H., Fukushi, K., Yamamoto, K., 2007. Comparison of sludge characteristics and PCR-DGGE based microbial diversity of nanofiltration and microfiltration membrane bioreactors. Chemosphere 67, 1543-1550.

[9] Edgar, R.C., 2010. Search and clustering orders of magnitude faster than BLAST. Bioinformatics 26, 2460-2461.

[10] Haas, B.J., Gevers, D., Earl, A.M., Feldgarden, M., Ward, D.V., Giannoukos, G., Ciulla, D., Tabbaa, D., Birren, B.W., Highlander, S.K., Petrosino, J.F., Sodergren, E., Methé, B., DeSantis, T.Z., Knight, R., 2011. Chimeric 16S rRNA sequence formation and detection in Sanger and 454-pyrosequenced PCR amplicons. Genome Res. 21, 494-504.

[11] Hai, F.I., Yamamoto, K., Lee, C.H. 2014. Membrane Biological Reactors: Theory, Modeling, Design, Management and Applications to Wastewater Reuse. IWA Publishing, London.

[12] Herlemann, D.P.R., Labrenz, M., Jürgens, K., Bertilsson, S., Waniek, J.J., Andersson, A.F., 2011. Transitions in bacterial communities along the $2000 \mathrm{~km}$ salinity gradient of the Baltic Sea. ISME J 5, 1571-1579.

[13] Hong, J., Li, W., Lin, B., Zhan, M., Liu, C., Chen, B.Y., 2013. Deciphering the effect of salinity on the performance of submerged membrane bioreactor for aquaculture of bacterial community. Desalination 316, 23-30.

[14] Jang, D., Hwang, Y., Shin, H., Lee, W., 2013. Effects of salinity on the characteristics of biomass and membrane fouling in membrane bioreactors. Bioresour. Technol. 141, $50-56$.

[15] Lay, W.C.L., Liu, Y., Fane, A.G., 2010. Impacts of salinity on the performance of high retention membrane bioreactors for water reclamation: A review. Water Res. 44, 21-40.

[16] Luo, W., Hai, F.I., Price, W.E., Guo, W., Ngo, H.H., Yamamoto, K., Nghiem, L.D., 2014. High retention membrane bioreactors: Challenges and opportunities. Bioresour. Technol. 167, 539-546.

[17] Luo, W.H., Hai, F.I., Kang, J.G., Price, W.E., Guo, W.S., Ngo, H.H., Yamamoto, K., Nghiem, L.D., 2015. Effects of salinity build-up on biomass characteristics and trace 
organic chemical removal: Implications on the development of high retention membrane bioreactors. Bioresour. Technol. 177, 274-281.

[18] Melin, T., Jefferson, B., Bixio, D., Thoeye, C., De Wilde, W., De Koning, J., van der Graaf, J., Wintgens, T., 2006. Membrane bioreactor technology for wastewater treatment and reuse. Desalination 187, 271-282.

[19] Nawaz, M.S., Gadelha, G., Khan, S.J., Hankins, N., 2013. Microbial toxicity effects of reverse transported draw solute in the forward osmosis membrane bioreactor (FOMBR). J. Membr. Sci. 429, 323-329.

[20] Nguyen, N.C., Chen, S.S., Nguyen, H.T., Ngo, H.H., Guo, W., Hao, C.W., Lin, P.H., 2015. Applicability of a novel osmotic membrane bioreactor using a specific draw solution in wastewater treatment. Sci. Total Environ. 518-519, 586-594.

[21] Nübel, U., Garcia-Pichel, F., Kühl, M., Muyzer, G., 1999. Quantifying microbial diversity: Morphotypes, 16s rRNA genes, and carotenoids of oxygenic phototrophs in microbial mats. Appl. Environ. Microbiol. 65, 422-430.

[22] Phattaranawik, J., Fane, A.G., Pasquier, A.C.S., Bing, W., 2008. A novel membrane bioreactor based on membrane distillation. Desalination 223, 386-395.

[23] Price, M.N., Dehal, P.S., Arkin, A.P., 2010. FastTree 2 - approximately maximum likelihood trees for large alignments. PLoS One 5, 1-10.

[24] Qiu, G.L., Ting, Y.P., 2013. Osmotic membrane bioreactor for wastewater treatment and the effect of salt accumulation on system performance and microbial community dynamics. Bioresour. Technol. 150, 287-297.

[25] Reid, E., Liu, X., Judd, S.J., 2006. Effect of high salinity on activated sludge characteristics and membrane permeability in an immersed membrane bioreactor. J. Membr. Sci. 283, 164-171.

[26] Shannon, M.A., Bohn, P.W., Elimelech, M., 2008. Science and technology for water purification in the coming decades. Nature 452, 301-310.

[27] Wijekoon, K.C., Hai, F.I., Kang, J., Price, W.E., Guo, W., Ngo, H.H., Cath, T.Y., Nghiem, L.D., 2014. A novel membrane distillation - thermophilic bioreactor system: Biological stability and trace organic compound removal. Bioresour. Technol. 159, 334-341.

[28] Yogalakshmi, K.N., Joseph, K., 2010. Effect of transient sodium chloride shock loads on the performance of submerged membrane bioreactor. Bioresour. Technol. 101, 7054-7061. 
[29] Zhang, L., Gao, G., Tang, X., Shao, K., Bayartu, S., Dai, J., 2013. Bacterial community changes along a salinity gradient in a Chinese wetland. Can. J. Microbiol. 59, 611-619.

[30] Zhang, T., Shao, M.F., Ye, L., 2012. 454 Pyrosequencing reveals bacterial diversity of activated sludge from 14 sewage treatment plants. J. ISME 6, 1137-1147. 


\section{LIST OF FIGURES}

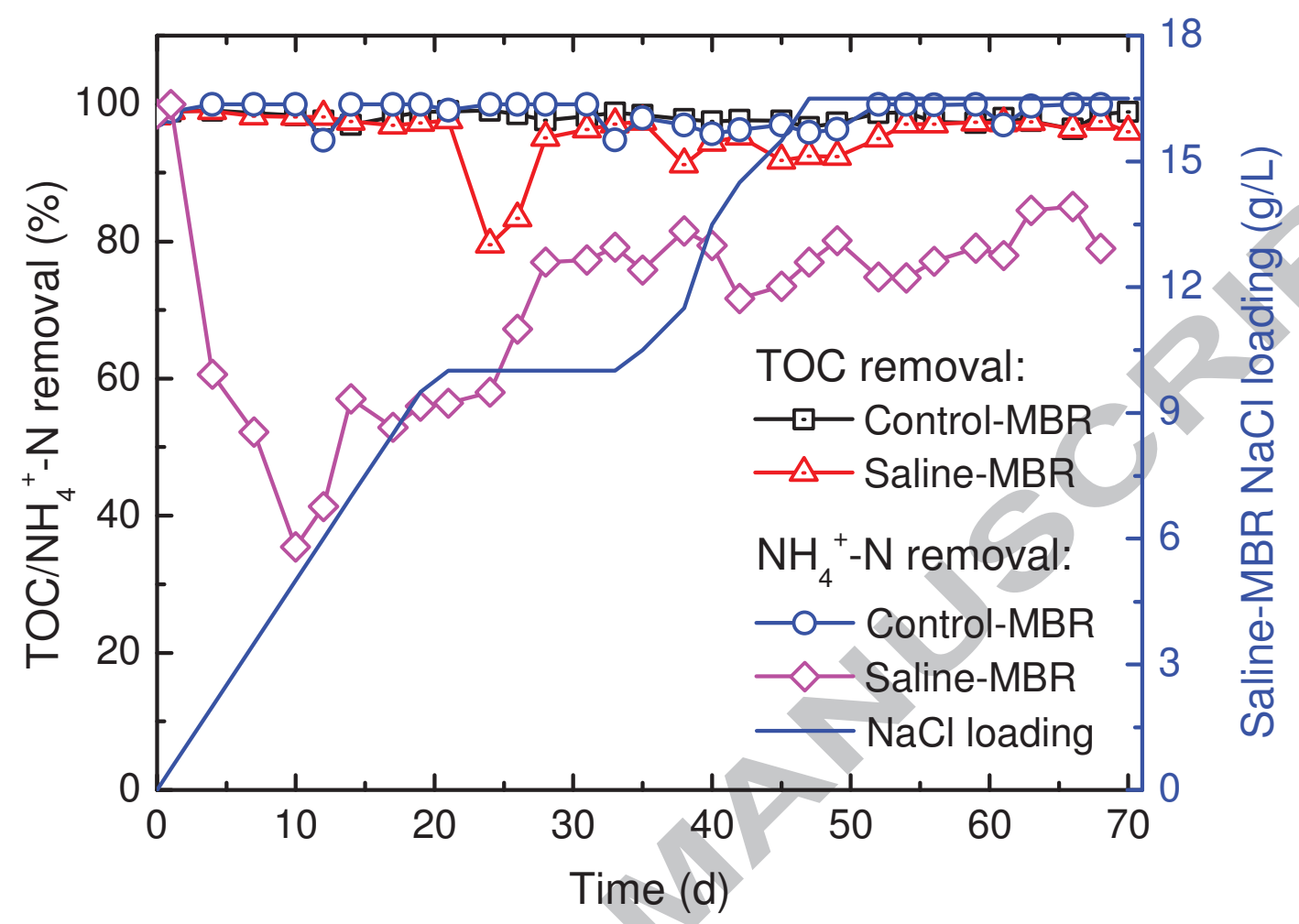

Fig. 1: TOC and $\mathrm{NH}_{4}{ }^{+}-\mathrm{N}$ removal by the control- and saline-MBRs. The influent $\mathrm{NaCl}$ loading of the saline-MBR was increased from 0 to $16.5 \mathrm{~g} / \mathrm{L}$ with a gradient of $0.5 \mathrm{~g} / \mathrm{L} \cdot$ day. Experimental conditions: initial MLSS $=5 \mathrm{~g} / \mathrm{L} ; \mathrm{SRT}=50 \mathrm{~d} ; \mathrm{HRT}=24 \mathrm{~h} ; \mathrm{DO}=5 \mathrm{mg} / \mathrm{L}$; temperature $=26.0 \pm 1^{\circ} \mathrm{C}$. 

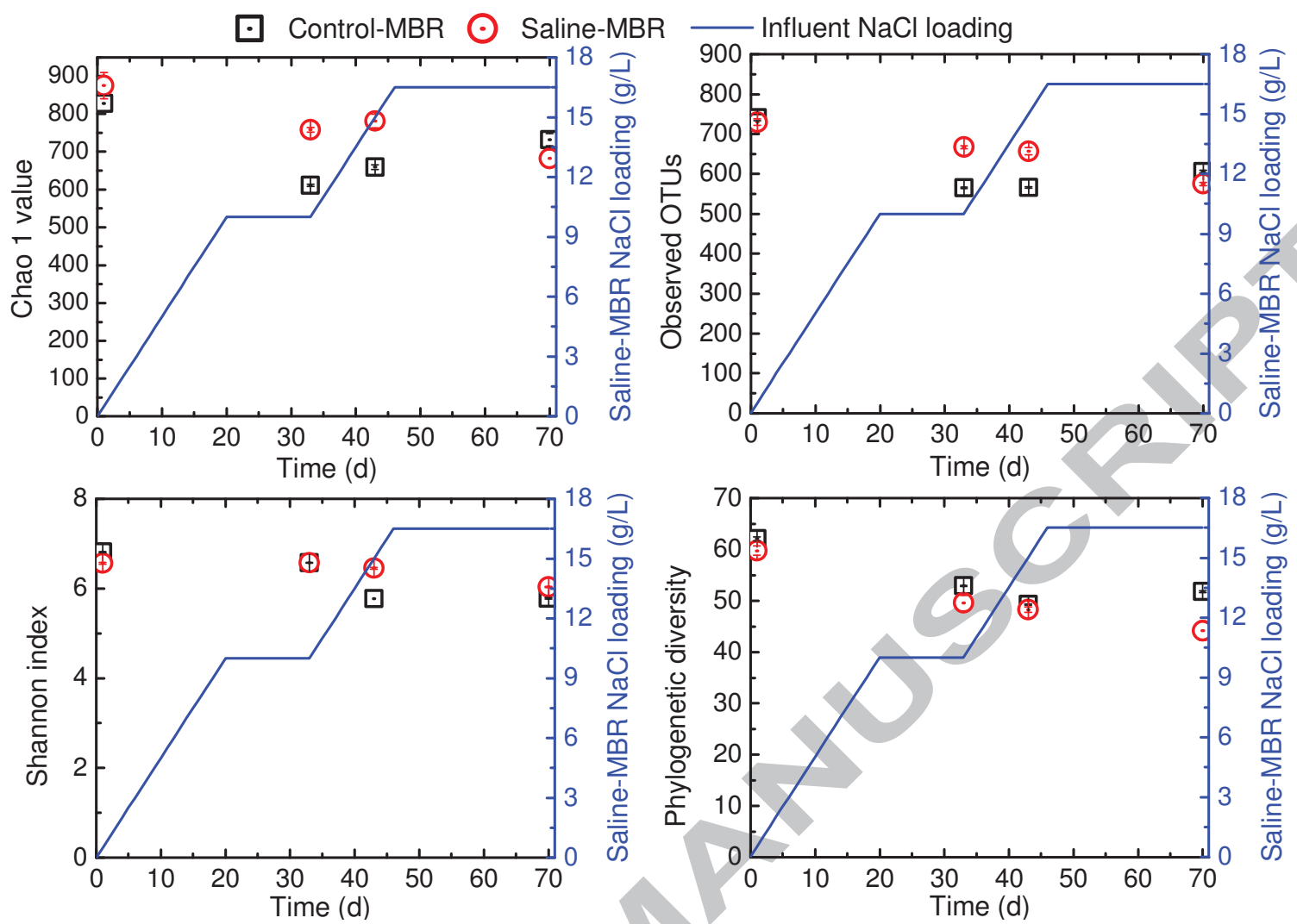

Fig. 2: The $\alpha$-diversity metrics (i.e. Chao 1 value, Observed OTUs, Shannon index, and phylogenetic diversity) of mixed liquor samples collected from the control- and saline-

MBRs. The $\alpha$-diversity metrics were determined at even sequencing depth of 13000 (i.e. the lowest sequences of each sample). Error bars represent the standard deviation from 10 repetitions of each sample. Experimental conditions are as described in the caption of Fig. 1. 


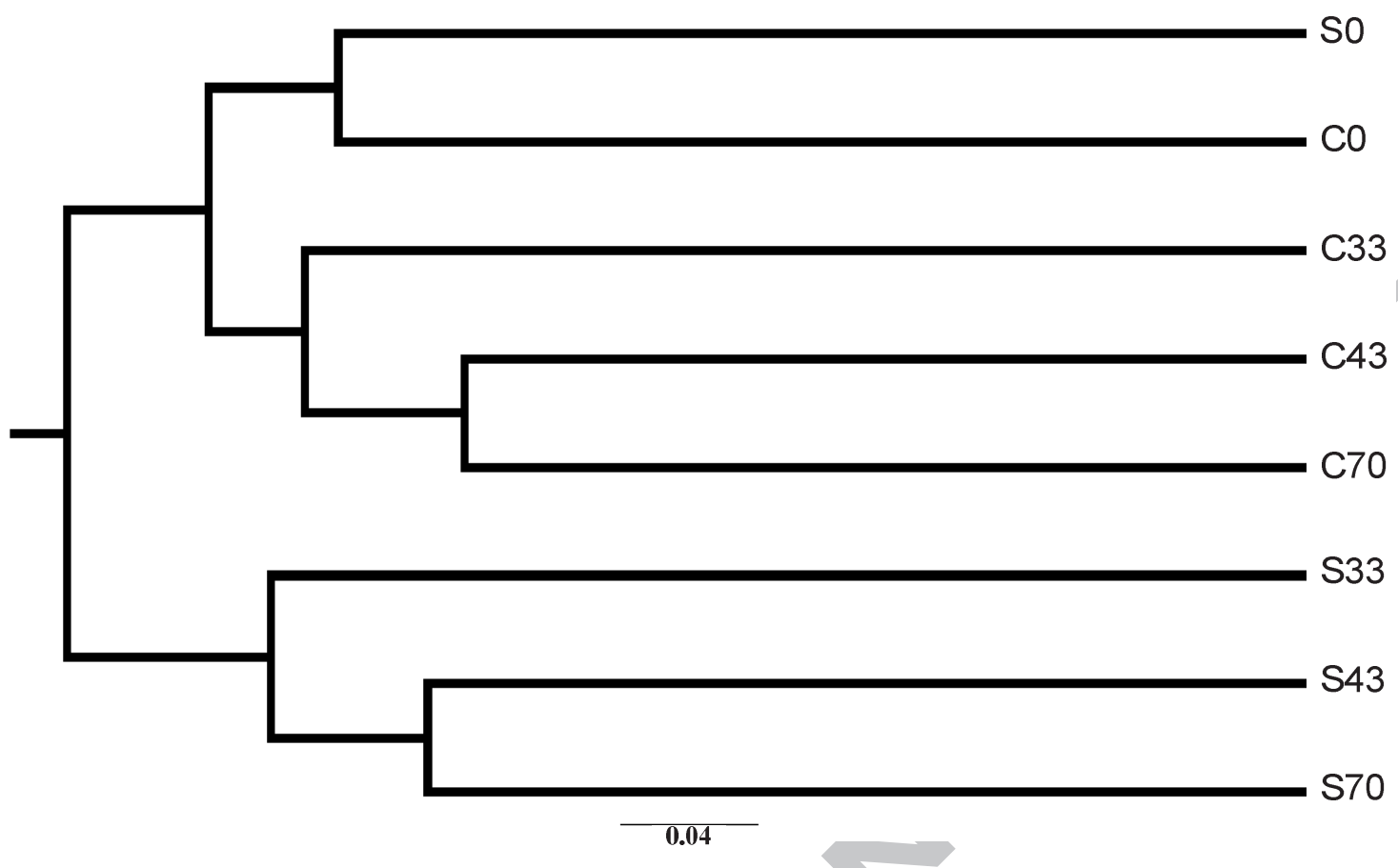

Fig. 3: Hierarchical clustering based on the unweighted UniFrac metric. The branch length represents the distance (indicated by scale bar) among the mixed liquor samples in UniFrac units. Labels on the branch indicate samples collected from the control-MBR (C0, C33, C43, and C70) and the saline-MBR (S0, S33, S43, and S70) on day 0, 33, 43, and 70 of the experiment, corresponding to $0,10,15$ and $16.5 \mathrm{~g} / \mathrm{L} \mathrm{NaCl}$ loading in the saline-MBR. Experimental conditions are as described in the caption of Fig. 1. 


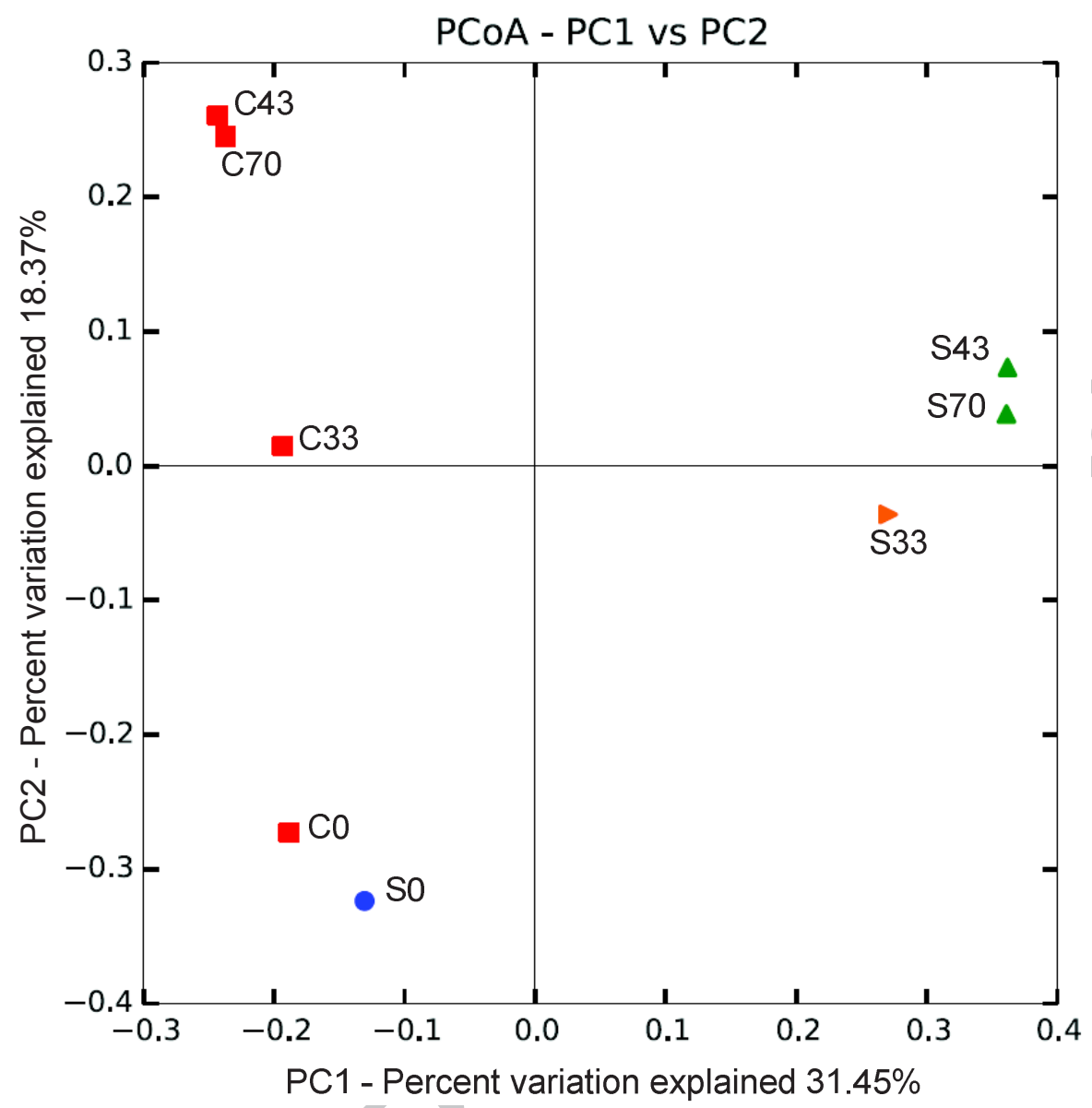

Fig. 4: Principal coordinate analysis (PCoA) based on the unweighted UniFrac metric. Mixed liquor samples were collected from the control-MBR $(\mathrm{C} 0, \mathrm{C} 33, \mathrm{C} 43$, and $\mathrm{C} 70)$ and the salineMBR (S0, S33, S43, and S70) on day 0, 33, 43, and 70 of the experiment, corresponding to 0, 10,15 and $16.5 \mathrm{~g} / \mathrm{L} \mathrm{NaCl}$ loading in the saline-MBR. Experimental conditions are as given in the caption of Fig. 1. 


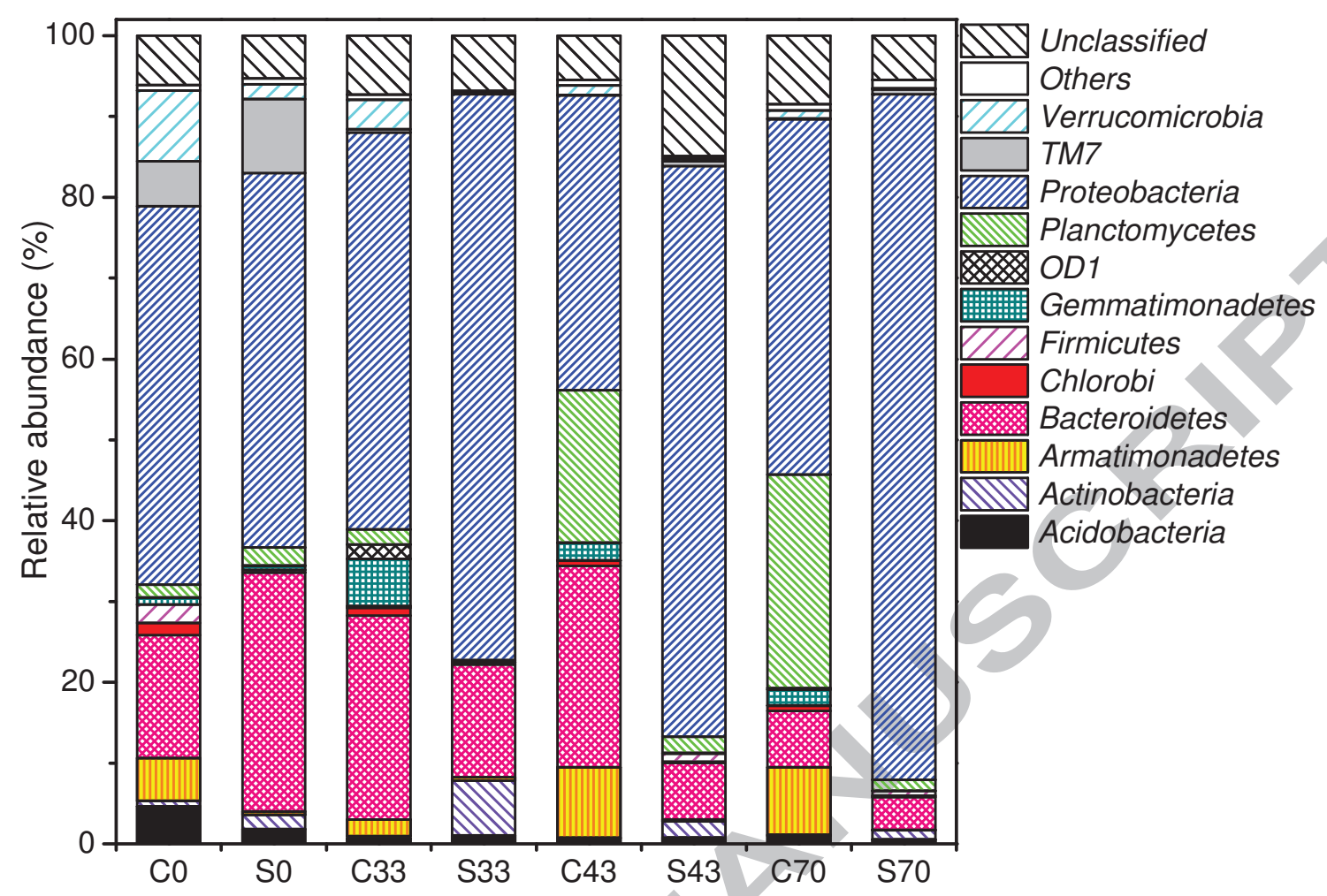

Fig. 5: Relative abundance of dominant phyla in the control-and saline-MBRs. Phyla with a relative abundance of less than $1.5 \%$ in all samples were grouped into "others". Samples were collected from the control-MBR (C0, C33, C43, and C70) and the saline-MBR (S0, S33, S43, and S70) on day $0,33,43$, and 70 of the experiment, corresponding to $0,10,15$ and $16.5 \mathrm{~g} / \mathrm{L}$ $\mathrm{NaCl}$ loading in the saline-MBR. Experimental conditions are as described in the caption of Fig. 1. 


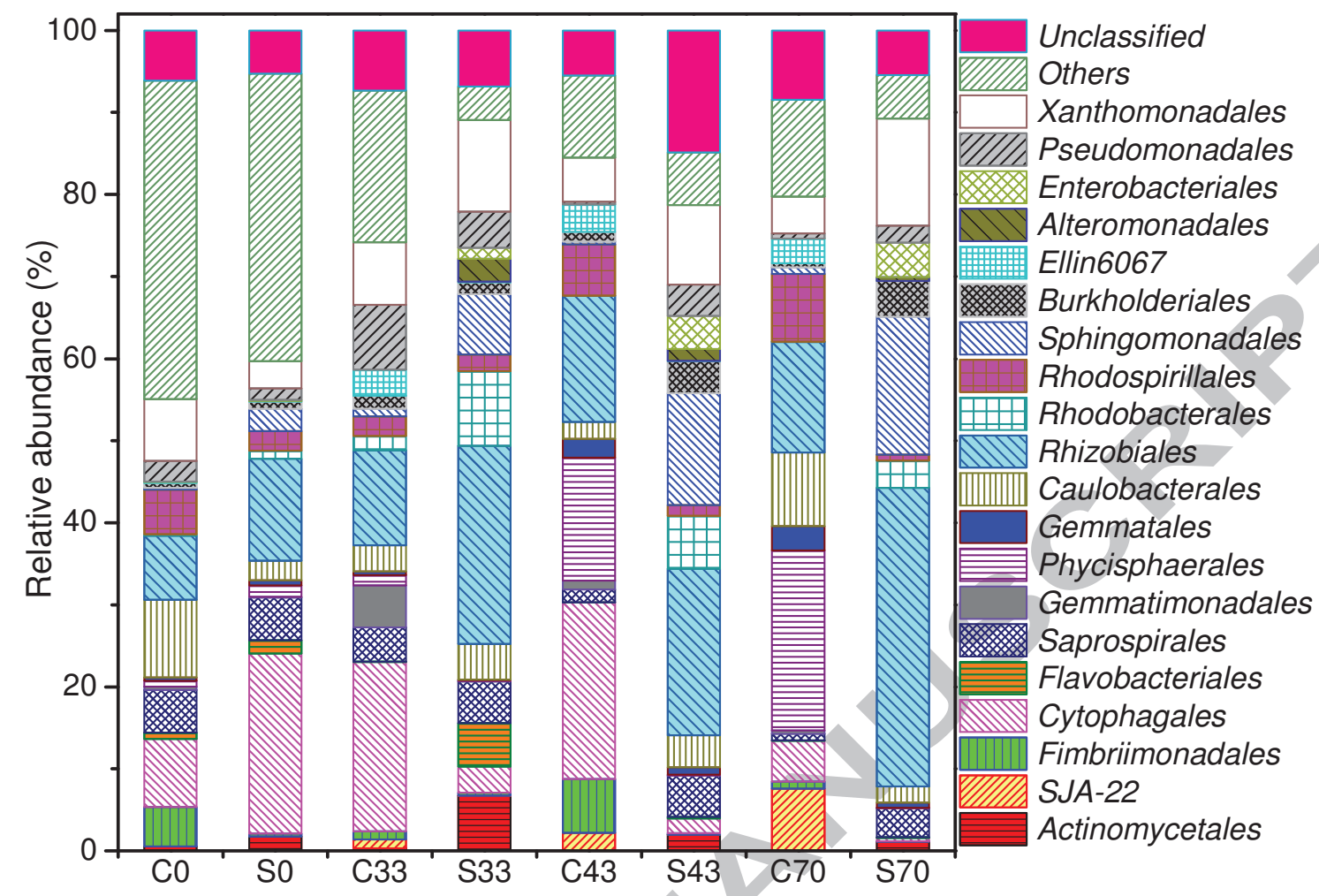

Fig. 6: Bacterial community structure in the control-and saline-MBRs at the order level.

Samples were obtained from the control-MBR (C0, C33, C43, and C70) and the saline-MBR (S0, S33, S43, and S70) on day $0,33,43$, and 70 of the experiment, corresponding to 0,10 , 15 and $16.5 \mathrm{~g} / \mathrm{L} \mathrm{NaCl}$ loading in the saline-MBR. Phylotypes with a relative abundance less than $3 \%$ and those only abundant in the samples at the beginning of the experiment (i.e. day 0 ) were grouped as "others". Experimental conditions are as detailed in the caption of Fig. 1. 


\section{Highlights}

- Salinity increase in the bioreactor affected MBR biological performance

- Elevated salinity did not reduce microbial diversity in the bioreactor

- Bacterial community in MBR could adapt to the elevated salinity condition

- Bacterial succession could facilitate the recovery of MBR biological performance 